\title{
Museos y periodistas. Análisis de la sala de prensa virtual como espacio de relaciones públicas
}

\author{
Guillem MarCa FrANCÉS \\ Universitat de Vic \\ guillem.marca@uvic.cat \\ Kathy Matilla \\ Universitat Ramón Llull \\ kathyms@blanquerna.url.edu \\ Santos M. Mateos Rusillo \\ Universitat de Vic \\ santos.mateos@uvic.cat
}

\begin{abstract}
Resumen:
Las rutinas de producción periodística se vieron alteradas con la aparición de Internet y la evolución de las fuentes 2.0. Se han extendido los espacios virtuales corporativos para los medios de comunicación, entendidos como herramienta básica de Relaciones Públicas. Los responsables de las organizaciones museísticas han entendido la necesidad de establecer un vínculo relacional con los periodistas en la red, a través de los sitios web oficiales de los museos. No obstante, concluimos que no facilitan los contenidos necesarios para transmitirlos de forma apropiada.
\end{abstract}

Palabras clave: medios de comunicación; museos; portal web; sala de prensa virtual.

\section{Museums and journalists. Analysis of the virtual pressroom as a public relations space.}

\begin{abstract}
:
News production routines were altered with the advent of the Internet and the evolution of the 2.0 technology sources. Corporate virtual spaces have broadly spread for the media, acting as a basic tool of Public Relations. Those who are responsible for museum organizations have understood the need for a relational link with reporters through the network, using the museums official websites. However, according to our results, we can conclude that these tools do not provide the appropriate content.
\end{abstract}

Key Words: Media; Museums; web portal; virtual pressroom; public relations

\section{Referencia normalizada:}

Marca Francés, G., Matilla, K. y Mateos Rusillo, S. M. (2014): Museos y periodistas. Análisis de la sala de prensa virtual como espacio de relaciones públicas. Historia y Comunicación Social. Vol. 19. Núm. Especial Marzo. Págs. 105-115.

Sumario: 1. Introducción. 1.1. Museos, prensa y contenidos internacionales. 2. Método. 3. Resultados. 3.1. Los museos disponen de sala de prensa virtual. 3.2. Los contenidos para periodistas. 3.3. La retroalimentación. 3.4. La prensa extranjera en el portal web de los museos. 4. Discusión. 5. Conclusiones. 6. Referencias bibliográficas. 


\section{Introducción}

En la actualidad, los nuevos medios de comunicación están teniendo un impacto dramático en el ámbito de las Relaciones Públicas (Wright y Drifka, 2010). La red se ha convertido en una herramienta estratégica para los departamentos de Relaciones Públicas, para promover y desarrollar sus relaciones con los medios y llegar a sus públicos clave (Kirat, 2007). Así pues, la alta prevalencia de la integración de Internet en las comunicaciones de las organizaciones no es discutible.

Muchos autores han estudiado las distintas etapas de esta integración y su influencia con los distintos públicos de la organización (Johnson, 1997, O’Malley e Iran, 1998, Holtz, 1999), en especial con los periodistas (Hachigian y Hallahan, 2003; Andrewes, 2006; González-Herrero y Ruiz de Valbuena, 2006, Pettigrew y Reber, 2010; Tekgroup y Bulldog Reporter, 2010). Los periodistas siempre han sido un público de interés para los profesionales de las Relaciones Públicas y, ahora, la comunicación con ellos es más fácil y adquiere una dimensión más rica. Hoy, las relaciones con los medios online se producen en múltiples niveles, que van más allá de la información de prensa, incluidas las observaciones y referencias personales en línea (Bajkiewicz, Kraus y Hong, 2011).

Ejerciendo de contenedor histórico de archivos y documentos, a la par que de gestores de relaciones con la prensa (Castillo, 2008), los espacios virtuales corporativos para los medios de comunicación se han mantenido y extendido desde un primer momento y son entendidos, hoy, como herramienta básica de Relaciones Públicas, adaptadas a las nuevas aportaciones tecnológicas de la ola 2.0. Estos espacios no sólo han afectado a la producción periodística en sí misma y a la dinámica de las acciones de Publicity y de las relaciones con los medios de comunicación, características de las Relaciones Públicas, sino que han permitido que los contenidos crucen fronteras.

\subsection{Museos, prensa y contenidos internacionales}

En los últimos tiempos, las relaciones entre las instituciones museísticas y sus públicos se han visto modificadas por factores diversos. Entre estos encontramos la evolución de las fuentes de financiación. Muchas instituciones culturales han pasado de nutrirse en exclusiva de aportaciones públicas a tener que buscar recursos en el sector privado (Twitchell, 2004). Como afirman Lampel, Lant y Shamsie (2000), las organizaciones culturales deben conciliar la producción cultural con las exigencias del mercado si quieren sobrevivir. Guste o no al sector, los museos de hoy compiten con espacios de ocio (tales como centros comerciales, parques temáticos, eventos deportivos, teatro y cine) por el tiempo de las familias y los turistas (McNichol, 2005). Esta transformación -de ser simples depositarios de artefactos sofisticados o interesantes a convertirse en industrias culturales- ha conducido a la adopción de prácticas de Publicidad y Relaciones Públicas que se emplean en otros ámbitos (Bantimaroudis, Zyglidopoulos y Symeou, 2010). 
Los museos, además de lanzar campañas publicitarias, precisan establecer relaciones con los medios de comunicación para conseguir notoriedad y reputación y construir una imagen positiva. Los responsables de prensa deben establecer relaciones de mutua confianza con los periodistas mediante un trabajo profesional y continuado, capaz de promover la publicación de informaciones, que son mediadas y destinadas a atraer visitantes a sus museos (Ibáñez-Cuenca y Baraybar-Fernández, 2011). Bantimaroudis, Zyglidopoulos y Symeou (2010) mantienen la hipótesis de que las apariciones en prensa establecen una fuerte influencia en la generación de visitas a los museos, aunque todavía no hayan podido demostrarlo científicamente.

Los museos no se han mantenido al margen de la evolución natural realizada por la mayoría de organizaciones en torno a Internet. En una entrevista publicada el año 2009 en el diario La Vanguardia, el prestigioso museólogo Philippe de Montebello reconocía que Internet impelía a los museos a reinventarse irremediablemente, obligados a comunicarse con las nuevas generaciones utilizando sus canales y su lenguaje. La irrupción de Internet en los museos, en la década de los años 90, ha abierto una nueva puerta que les ha permitido desplegar todo su potencial comunicativo al crear experiencias que van más allá de sus cuatro paredes, rompiendo así la Quinta Pared que los separaba tanto física como mentalmente (Castells, 2001; Carr y Paul, 2011). Sus consecuencias han sido fundamentalmente el florecimiento de una nueva relación entre las instituciones museísticas y sus públicos, basada en un tipo de comunicación dialógica que les permite caminar hacia la plena interacción (Ingenhoff y Koelling, 2009; Capriotti y Pardo Kuklinski, 2012).

Internet ha permitido incorporar herramientas que facilitan las relaciones con sus distintos públicos, entre los que se incluyen los periodistas. Para los profesionales de la información, las salas de prensa han devenido una sección imprescindible en las webs de los entes públicos (Xifra, 2011). Los periodistas españoles consideran las páginas web institucionales como las más útiles para realizar su trabajo (Xifra, 2011).

En este estudio se han revisado las herramientas online puestas a disposición de los periodistas en el ranking de los cien museos del mundo que recibieron más visitas durante el año 2011 (The Art Newspaper, 2012: 35 y 37). Los visitantes de estos museos son, en la mayoría de los casos, turistas procedentes de otros países. En nuestro estudio tratamos de establecer la eficacia de dichas herramientas online, cuando sus usuarios no pertenecen al país en el que se asienta el museo, usándose la web cómo una herramienta facilitadora de relaciones con públicos de otros países, en nuestro caso, periodistas. Para ello, nos planteamos cuatro preguntas de investigación:

Pi1: ¿Los web corporativos de los museos disponen de un espacios con contenidos de interés para los periodistas?

Pi2: ¿Qué utilizan los museos para transmitir contenidos en sus webs corporativos y para comunicarse con los periodistas? 
Pi3: ¿Los portales web de los museos incluyen herramientas que permiten un feedback con los medios, como por ejemplo direcciones de correo electrónico, blogs, foros, etc.?

Pi4: ¿Cuál es la proporción de periodistas foráneos que utiliza las herramientas online del museo y qué influencia ha tenido el uso de tales herramientas para la aparición en la prensa de otros países?

\section{Método}

En primer lugar, analizamos los portales web seleccionados. A través de un análisis de contenido (Krippendorff, 1990), diseñamos un cuestionario ad hoc para dar respuesta a nuestros interrogantes.

Posteriormente, llevamos a cabo un estudio descriptivo transversal sobre los portales web oficiales de diversos museos, en su versión en inglés. Para la selección de la muestra utilizamos el listado de referencia Top100 publicado por la revista (The Art Newspaper, 2012: 35 y 37), que incluye los museos con mayor número de visitantes, que fueron analizados en su totalidad.

Tras identificar los dominios oficiales de Internet de cada uno de los museos objeto de estudio, pudimos verificar que todos cuentan con una web oficial. Posteriormente, el cuestionario de análisis fue completado por dos investigadores independientes. Se analizaron las discrepancias y se alcanzó un consenso entre encuestadores. La información fue introducida en una base de datos construida específicamente para este estudio.

Para el análisis estadístico se utilizaron porcentajes y proporciones para las variables cualitativas y medias para las variables de tipo cuantitativo. Para el análisis de los datos se utilizó el paquete SPSS $14^{\mathrm{a}}$ edición.

En segundo lugar, además de identificar los dominios oficiales, identificamos los correos electrónicos de los responsables de comunicación o de prensa de cada museo, a de investigación planteada quienes se remitió un cuestionario que diera respuesta a la cuarta pregunta en nuestro estudio. Este cuestionario, incrustado en el mismo correo, era breve y contaba únicamente con cuatro preguntas cerradas, con el objetivo de facilitar la respuesta al entrevistado. Se cursó entre los meses de marzo y abril de 2012, en tres oleadas consecutivas, separadas por diez días cada una de ellas. Los datos se reunieron en una tabla y fueron analizados también con el paquete SPSS $14^{\mathrm{a}}$ edición. Para el análisis estadístico se utilizaron porcentajes y medias para las variables de tipo cuantitativo. 


\section{Resultados}

\subsection{Los museos disponen de sala de prensa virtual}

Para poder contextualizar la existencia de espacios específicos para la prensa, en el actual contexto de establecimiento de relaciones con los distintos públicos en el que se ven inmersos los museos, en primer lugar analizamos si en la página principal del museo existían enlaces específicos para los diferentes públicos. Únicamente en siete ocasiones $(7 \%)$ se constató que no existía este tipo de diferenciación, mientras que en el resto $(93 \%)$ sí pudimos identificarla. De entre los museos que diferenciaban la acogida de distintos públicos, los más destacados eran los profesionales ( $81 \%)$, seguidos de los periodistas $(55 \%)$, los voluntarios $(29 \%) \mathrm{y}$, por último, el turismo $(30 \%)$. Debemos aclarar que bajo el término turismo encontrábamos, muchas de las veces, información útil para agencias de viajes y tour operadores. Además, en 46 ocasiones (46\%) identificamos otros tipos de públicos, como escuelas, familias, patrocinadores o mecenas, entre otros, a los que se hacía referencia.

Aunque únicamente en 54 casos (54\%) se identifica la existencia del público prensa en la página principal, el $81 \%$ de los museos analizados cuentan con un espacio específico para los periodistas. Los nombres que recibe este espacio son diversos, destacando "press" en 25 casos (25\%), "press room" en 22 casos (22\%), "press office" en 8 casos ( $8 \%$ ) y "media" en 6 casos (6\%). Otros como "press enquires", "press area", "press release" o "press service" aparecen únicamente en dos 2 ocasiones cada uno $(2 \%) \mathrm{y}$, además, hay 12 casos (12\%) en los que los nombres recibidos por el espacio dedicado a los profesionales de la información son distintos al resto ("press and media", "press coverage", "newsroom", "media room", etc.).

Mayoritariamente, el acceso a los espacios para la prensa son muy directos. En 57 casos (57\%), el acceso a la sala de prensa se puede realizar con un solo clic. Este dato puede generar cierta controversia, ya que es algo mayor que el número de museos (4 casos, $4 \%$ ) que identificaban a los periodistas como público en la página principal. La diferencia concierne a que el acceso a alguna de las salas de prensa es directo desde la home, mientras que en algunos casos también es directo, pero a través de un desplegable sobre el que no es necesario realizar un clic. Son menos los casos en los que deben realizarse dos clics $(23,23 \%)$ y únicamente en un solo caso $(1 \%)$ es necesario realizar tres clics para acceder a la zona de los profesionales de prensa.

Otro elemento que hemos tenido en consideración es el nivel de privacidad de los contenidos de los espacios para la prensa. En 32 casos (39,5\%) son espacios de libre acceso para todos los públicos, en 11 de los casos $(13,6 \%)$ la información es totalmente restringida y, en su mayoría (38 casos, 47\%), tienen libre acceso, pero con zonas de información restringida bajo necesidad de registro, como la descarga de imágenes en alta resolución.

En 96\% de los casos la actualización de la información presentada en las zonas de prensa sigue un patrón cronológico. La mayoría de actualizaciones se realizan 
mensualmente ( 54 casos, $66,7 \%)$ y en muy pocos casos semanalmente (4 casos, $4,9 \%)$ o trimestralmente ( 2 casos, $2,5 \%)$. En 21 casos $(25,9 \%)$ no hay fecha de las actualizaciones, pero puede seguirse la existencia del patrón cronológico, ya que la mayoría de informaciones se refieren a exposiciones con intervalos temporales de apertura y cierre específicos.

\subsection{Los contenidos para periodistas}

Los contenidos que más se repiten en las zonas para periodistas de los museos son, en primer lugar, las agendas ( 74 casos, $91,4 \%$ ), seguidos por la historia del museo (63 casos, $77,8 \%$ ) y las notas de prensa (60 casos, $74,1 \%$ ) son más ocasionales.

Aunque la presencia de imágenes está extendida en todas las zonas de prensa de los museos estudiados, el formato de éstas abarca desde los clásicos .jpg o .tif, hasta incrustaciones en películas flash o documentos $p d f$, que no permiten su descarga, siendo muy pocos los museos con formatos de píxeles, de los que identificamos únicamente 10 casos $(12,3 \%)$ en alta resolución. Los demás museos emplazan a los periodistas a solicitar por correo electrónico las imágenes en alta definición.

La situación es similar en lo que hace referencia a los vídeos, siendo únicamente 30 los espacios para profesionales con vídeos, 2 de los cuales $(2,5 \%)$ permiten su descarga, mientras que los 28 restantes (37\%) únicamente son visibles en línea (streaming).

Para acceder a los contenidos -que como hemos observado, son mayoritariamente agendas, historia de la institución o notas de prensa-, 68 de las zonas de periodistas $(84 \%)$ cuentan con un buscador, aunque en algunas de las ocasiones la base de búsqueda es todo en site, en vez de limitarse a la zona profesional.

\subsection{La retroalimentación}

La mayoría de espacios reservados a periodistas identifican a los responsables del departamento dedicados a esta función de contacto. En 19 casos $(23,5 \%)$ identifican a un solo responsable, en 14 casos (17,35\%) identifican a dos responsables y en 28 casos (34,6\%) a más de dos responsables. En 17 casos no hay responsables identificados con los que contactar.

Las herramientas de la retroalimentación son el correo postal (72 casos, 89,3\%), el correo electrónico ( 60 casos, $74,1 \%$ ), el teléfono ( 79 casos, $97,6 \%$ ), el fax (36 casos, $44,4 \%$ ) y el uso de un formulario de contacto (38 casos, $48,1 \%$ ).

\subsection{La prensa extranjera en el portal web de los museos}

La tasa de respuesta de la encuesta dirigida a los responsables de comunicación de los cien museos, segunda parte de nuestro estudio, fue del 31\%. Si bien la mayoría de los encuestados $(80,6 \%)$ reconoció que desde la creación de la sala de prensa virtual no tenían la percepción de un aumento de apariciones en prensa extranjera, 
un $71 \%$ afirmó que más de un $40 \%$ de los visitantes de la sala de prensa virtual eran periodistas extranjeros. La mayoría de encuestados (85\%) respondieron "no lo sé" cuando se les preguntó sobre qué proporción de periodistas extranjeros utilizaban las herramientas 2.0 del museo. En cambio, un $63 \%$ de los encuestados afirmó llevar algún tipo de control sobre la procedencia de los periodistas que visitan sus salas de prensa virtuales.

\section{Discusión}

Este artículo analiza las salas de prensa de los museos de alcance internacional en un entorno tecnológico altamente evolucionado, desde que se realizaron los primeros estudios sobre esta tipología de espacios a finales de la década de los años noventa del siglo Xx. El hecho de que ocho de cada diez museos tengan un espacio destinado a los periodistas demuestra la necesidad de establecer vínculos con la prensa por parte de los profesionales de Relaciones Públicas en el contexto actual de la industria cultural, concretamente en el caso de los museos. Se constata que los museos han entendido la necesidad de establecer vínculos con sus públicos y que, para llegar a cada uno de ellos, deben adaptar los mensajes y los contenidos a transmitir. Han sido más de diez las tipologías de públicos identificadas, que intuimos que coinciden con razones culturales de cada país, de la misma forma que, probablemente, también coinciden con este tipo de cuestiones los distintos términos con los que se designan los espacios virtuales destinados a los periodistas. Con estos primeros datos, constatamos que los espacios online para periodistas son un elemento extendido como herramienta de Relaciones Públicas en los museos más visitados a nivel internacional.

Como afirma Castillo (2008), las salas de prensa de los museos ejercen el papel de archivo documental y de gestión para periodistas, administrando agendas de eventos, recopilando notas de prensa y ejerciendo de contenedor audiovisual, en el que las imágenes de las obras son el formato protagonista. De forma mayoritaria las actualizaciones se realizan mensualmente, facilitando de esta forma el establecimiento de rutinas por parte del periodista. Destacamos que el acceso a una parte de la información -sobre todo imágenes- es restringido, lo que permite a los profesionales de Relaciones Públicas una monitorización de los periodistas que visitan el espacio y el tipo de información al que tienen acceso. Diversos estudios verifican que esta función documental es la más valorada por los periodistas (Callison, 2003; González-Herrero y Ruiz de Valbuena, 2006; Xifra, 2011).

Para poder establecer feedback entre periodistas y relacionistas públicos, se observa que las herramientas aportadas no han variado considerablemente desde los primeros estudios publicados sobre la materia. El correo electrónico, los formularios autocumplimentados y el teléfono son las herramientas más repetidas (Kirat, 2007). En cambio, no se incluyen ni foros, ni blogs específicos para periodistas. Sí que existen enlaces a redes sociales, aunque sin segmentación de públicos. 
El estudio que tenemos entre manos, proporciona un punto de partida sobre el uso de los espacios para los periodistas en la industria cultural de alcance internacional, aportando como novedad las percepciones de los responsables de comunicación de los museos analizados. En éstas podemos observar que la web y, específicamente, las salas de prensa virtuales son espacios fácilmente monitorizables, en los que se identifica que casi la mitad de los visitantes periodistas son extranjeros. Mayhall (2003) argumenta que Internet puede ser utilizado en la profesión de Relaciones Públicas como una herramienta de comunicación, de desarrollo profesional y sobre todo de investigación y evaluación.

Como comentaba Holtz (1999), el beneficio real de establecer relaciones con los medios a través de Internet viene de la focalización de éstos como público especializado y de la elaboración de una estrategia que aborde específicamente sus necesidades. La misión del área de relaciones con los medios de comunicación es ayudar a los periodistas a hacer su trabajo. Este objetivo es plenamente coherente con el objetivo más amplio de las Relaciones Públicas, entendidas como la gestión de la relación entre la organización y sus diversos públicos. Hoy, podemos afirmar que los museos deben extender esta función más allá del país en el que se encuentra su sede física, facilitando así la creación de notoriedad e imagen.

Blogs y foros están ganando terreno a los medios tradicionales, pero estos últimos todavía gozan de más precisión, credibilidad, ética y veracidad (Wright y Drifka, 2010). Así, resulta clave para los responsables de comunicación de los museos mantener vínculos estrechos con los periodistas. A diferencia de lo que ocurre en otros estudios similares, en los que los sujetos del análisis de contenidos son páginas corporativas de empresas cotizadas en bolsa, en el ámbito museístico las dudas sobre la credibilidad de la información de las salas de prensa virtuales (Pettigrew y Reber, 2010) quedan en un segundo término, ya que la transcendencia de la materia prima informativa que se maneja es mucho más estable, y se ve casi siempre apoyada por elementos audiovisuales, que pueden ser, en muchos casos, el material buscado por el periodista.

\section{Conclusiones}

Aunque Internet tiene defensores y detractores entre los periodistas, la rápida integración en las redacciones (Sarrica et alt., 2010) es debida a la necesidad de fuentes de información especializada oficiales, facilitadas en la nube de datos.

En conclusión, el valor universal del patrimonio cultural conservado en los museos se puede convertir en algo realmente universal, si se utiliza Internet como vehículo privilegiado para difundir internacionalmente toda esa riqueza cultural. Llenar de contenidos los espacios destinados para la prensa, pensando en los periodistas extranjeros, es sin duda una de las estrategias para pasar de lo local a lo global, de la nacional a lo internacional. 


\section{Bibliografía}

ANDREWES, J. (2006). "Developing an online press office for Cardiff Council: Principles of excellence". En: Journal of Communication Management, $\mathrm{n}^{\circ} 10$ (2). p. 156-173. [24-07-2013].

BAJKIEWICZ, TE.; KRAUS, JJ.; HONG, SY. (2011). "The impact of newsroom changes and the rise of social media on the practice of media relations". En: Public Relations Review, $\mathrm{n}^{\circ}$ 37(3). p. 329-331. [6-07-2013].

BANTIMAROUDIS, P.; ZYGLIDOPOULOS, S.; SYMEOU, PC. (2010). “Greek Museum Media Visibility and Museum Visitation: An Exploration of Cultural Agenda Setting". En: Journal of Communication, no60(4). p. 743-757. [12-072013].

CALLISON, C. (2003). "Media relations and the Internet: how Fortune 500 company web sites assist journalists in news gathering". En: Public Relations Review, ${ }^{\circ}{ }^{29}$, p. 29-41. [26-07-2013].

CAPRIOTTI, P.; PARDO KUKLINSKI, H. (2012). "Assessing dialogic communication through the Internet in Spanish museums". En: Public Relations Review, In Press, Corrected Prof. [27-07-2013].

CARR, E.; PAUL, M. (2011). Rompiendo la quinta pared: Marketing para las artes en la era digital. Madrid: Ediciones y Publicaciones Autor.

CASTELLS, M. (2001). "Museums in the Information Era. Cultural connectors of time and space". En: ICOM News, Special Issue, p. 4-7. http://icom.museum/fileadmin/user_upload/pdf/ICOM_2001/ICOM_ENG_10_2001_small.pdf. [22-072013].

CASTILLO, A. (2008). "La comunicación empresarial en internet". En: Icono 14, $\mathrm{n}^{\circ}$ 14, Madrid. http://www.icono14.net/revista/num11/141102.pdf. [25-07-2013].

GARRISON, B. (1999). Journalists' Perspectives on Online Information-Gathering Problems. Paper presentado en: AEJMC Southeast Colloquium, Lexington (KY), Marzo. http://com.miami.edu/car/lexington.pdf. [24-07-2013].

GONZÁLEZ-HERRERO A.; RUIZ DE VALBUENA, M. (2006). "Trends in online media relations: Web-based corporate press rooms in leading international companies. En: Public Relations Review, $\mathrm{n}^{\circ}$ 32(3). September, p. 267-275. [22-07-2013].

HACHIGIAN, D.; HALLAHAN, K. (2003). "Perceptions of public relations web sites by computer industry journalists". En: Public Relations Review, $\mathrm{n}^{\mathrm{o}}$ 29(1). March, p. 43-62. [22-07-2013].

HOLTZ, S. (1999). Public Relations on the net: Winning strategies to inform and influence the media, the investment community, the government, the public, and more. New York: AMACOM.

IBÁÑEZ-CUENCA, JA.; BARAYBAR-FERNÁNDEZ, A. (2011). "Fuentes 2.0 y periodistas. Transformaciones en la comunicación museística". En: El Profesional de la Información, $\mathrm{n}^{\mathrm{o}}$ 20(6). p. 634-638. [22-07-2013].

INGENHOFF, D.; KOELLING, AM. (2009). "The potential of Web sites as a relationship building tool for charitable fundraising NPOs". En: Public Relations Review, no 35(1), March. p. 66-73. [24-07-2013]. 
JOHNSON, MA. (1997). "Public Relations and technology: Practitioner perspectives". En: Journal of Public Relations Research, no 9(3). p. 213-236. [26-072013].

KIRAT, M. (2007). "Promoting online media relations: Public relations departments' use of Internet in the UAE". En: Public Relations Review, $\mathrm{n}^{\mathrm{o}}$ 33(2). June, $\mathrm{p}$. 166-174. [22-07-2013].

KRIPPENDORFF, K. (1990). Metodología de análisis de contenido. Teoría y práctica. Barcelona: Paidós.

LAMPEL, J.; LANT, T.; SHAMSIE, J. (2000). "Balancing Act: Learning from Organizational Practices in Cultural Industries". En: Organization Science, $\mathrm{n}^{\circ}$ 11(3). p. 263-269. [22-07-2013].

MAYHALL, RM. (2003). Public Relations on the Internet. En: http://www.hieran. com/netpr/netpr.doc. [22-07-2013].

MCNICHOL, T. (2005). "Creative marketing strategies in small museums: up close and innovative". En: International Journal of Nonprofit and Voluntary Sector Marketing. $\mathrm{n}^{\circ}$ 10. p. 239-247. [24-07-2013].

O'MALLEY, M.; IRAN, T. (1998). "Public Relations and the Web: Measuring the effect of interactivity, information, and access to information in Web sites". Paper presentado en: Annual Meeting of AEJMC, Public Relations Division, Baltimore (MD), Agosto. [22-07-2013].

PETTIGREW, J E.; REBER, BH. (2010). "The New Dynamic in Corporate Media Relations: How Fortune 500 Companies Are Using Virtual Press Rooms to Engage the Press". En: Journal of Public Relations Research, no 22(4). p. 404-428. [24-072013].

SARRICA, M.et alt. (2010). "The Early Stages of the Integration of the Internet in EU Newsrooms". En: European Journal of Communication, $n^{\circ}$ 25(4). p. 413-422. [24-07-2013].

Tekgroup and bulldog reporter (2010). "2010 Journalist Survey on Media Relations Practices". En: http://a2.mndcdn.com/image/upload/t_attachment/wv5jbgsyeozhmncdmuhk.pdf. [1-08-2013].

The Art Newspaper $\mathrm{n}^{\circ} 234$, (15-04-2012).

WRIGHT, DK.; DRIFKA, MA. (2010). "An Analysis of New Communications Media Use in Public Relations: Results of a Five-Year Trend Study". En: Public Relations Journal, $\mathrm{n}^{\mathrm{o}}$ 4(2). Spring. [12-07-2013].

TWITCHELL, J.B. (2004). Branded Nation: The Marketing of Megachurch, College, Inc., and Museumworld. New York: Simon and Schuster.

XIFRA, J. (2011). "Subsidios informativos y función documental de las salas de prensa online de los ministerios españoles". En: El Profesional de la Información, $n^{\circ} 20(3)$. p. 270-275. [10-07-2013]. 


\section{Los autores}

Guillem Marca Francés. Doctor en Publicidad y Relaciones Públicas por la Universitat Rovira i Virgili, es licenciado en Bellas Artes por la Universitat de Barcelona y licenciado en Publicidad y Relaciones Públicas por la Universitat Ramón Llull. Actualmente ejerce de profesor en la Universitat Rovira i Virgili y la Universitat de Vic en la que coordina el Grado en Publicidad y Relaciones Públicas. Combina la docencia y la investigación en comunicación con tareas de consultoría para distintas instituciones y empresas.

Kathy Matilla. Doctora en Comunicación por la Universitat Ramón Llull, es licenciada en Geografía e Historia, especialidad Historia del Arte, y Diplomada en Relaciones Públicas por la Universitat de Barcelona. Actualmente pertenece al claustro de profesores de la Universitat Ramón Llull. Combina la docencia y la investigación en comunicación con la consultoría estratégica en comunicación para distintas organizaciones en varios países.

Santos M. Mateos Rusillo. Doctor en Historia del Arte por la Universitat de Barcelona, es licenciado en Geografía e Historia por la misma universidad. Actualmente ejerce de profesor en la Universitat de Vic y de consultor de la Universitat Oberta de Catalunya. Su campo de investigación se centra en la comunicación y mediación cultural de los museos y del patrimonio cultural. 